\title{
Investigation of chemical contamination after a strong flash flood (2018) in the mining area of the Orbiel catchment (France)
}

\author{
PHILIPPE BEHRA ${ }^{1}$, GAUTHIER DELPLACE ${ }^{2}$, EVA \\ SCHRECK $^{3}$, PRISCIA OLIVA ${ }^{4}$ AND JÉRÔME VIERS ${ }^{2}$ \\ ${ }^{1}$ Institut National Polytechnique de Toulouse \\ ${ }^{2}$ Université Paul Sabatier \\ ${ }^{3}$ Géosciences Environnement Toulouse \\ ${ }^{4}$ laboratoire Geosciences Environnement Toulouse \\ Presenting Author: philippe.behra@ensiacet.fr
}

The Orbiel valley hosts the old mining-district of Salsigne, taped until 2004. It was the largest European gold and largest world arsenic mine. This mining activity has generated millions of tons of wastes, stored at various locations in the catchment. Due to its location, the Orbiel catchment shows high wind erosion and large surface runoff due to the local Mediterranean flash flood. Waste deposits can thus contribute to the migration of contaminants to the atmosphere, ground or surface waters by infiltration and/or surface runoff, but also to the biosphere. In October 2018, a very strong flash flood occurred (flow increasing from $1 \mathrm{~m}^{3} / \mathrm{s}$ to more than $400 \mathrm{~m}^{3} / \mathrm{s}$ in few hours), killing 15 people and carrying many sediments from upstream to downstream after flooding the major bed of the Orbiel river and two of its tributaries, the Grésillou and the Russec rivers, all of them passing through old mine or wastes areas. After this catastrophic event, water, soils and sediments were regularly sampled from 2018 to 2020 . The objective of this study was to better understand the fate and fluxes of the different chemicals, stored in this watershed. For this purpose, we used a geochemical approach based on element analyses of soil, sediment and surface water samples. All samples were taken at different locations along the Orbiel, Grésillou and Russec rivers. Classical parameters such as $\mathrm{pH}$, conductivity... were measured in-situ after sampling. Water samples were filtered and acidified in-situ too. Metals and metalloids of samples were analysed by ICP-MS, after acid microwave mineralisation. Results showed that element concentrations increased from upstream to downstream. For example, arsenic concentration increased from 1 to $80 \mu \mathrm{g} / \mathrm{L}$ in water and 8 to $800 \mu \mathrm{g} / \mathrm{g}$ in sediments sampled in the riverbed of Orbiel; water concentration can be greater than $100 \mu \mathrm{g} / \mathrm{L}$ and sediment content higher than $20 \mathrm{mg} / \mathrm{g}$ in tributaries. In this presentation, we will show how element concentrations can dramatically change depending on location due to the presence of wastes and how element tracers and ratios can help to identify contamination sources and estimate element fluxes. 